\title{
Science Under Siege: The Myth of Objectivity in Scientific Research
}

\author{
A.B.R. THOMSON, MD, PHD, FRCPC, FACP
}

'S CIENCE UNDER SIEGE: THEMYTH OF OBJECTIVITY IN SCIENtific Research' was brought to my attention by my friend and colleague, Noel B. Hershfield, who with wisdom, wit and common sense often helps all those who wish "to seek, to strive, to find and not to yield" (Tennyson), to cherish our choices with "the milk of human kindness" (Shakespeare).

So often the reviewers of books will feel some obligation to find some merit in the text, recognizing the hours of effort which the contributors have undertaken to bring the work to its conclusion. 'Science Under Siege' is not a book to be taken lightly, is not a book to be scanned or thumbed through, and not really a book to be enjoyed. It is certainly not a book to be taken for granted. However, it is a book worthy of reading, discussion and dispute by every member of the scientific community. It will upset, cajole, anger and embarrass. Yet, its contents must be considered and the issues raised must be addressed.

Perhaps Ursula M. Franklin of the University of Toronto is correct when she writes in the introduction, "Within our time science plays a pivotal role, comparable to the role of religion in the Middle Ages. In a contemporary setting, science provides the knowledge of how to live, how to approach and solve problems, and how to understand the universe and its workings. ... I consider knowledge a common good, and not

Correspondence: Dr A.B.R. Thomson, University of Alberta, 519 Robert Newton Building, Edmonton, Alberta T6G 2C2

This book was based on a four-part series produced by Beth Savan for CBC Radio 'Ideas' which was awarded the Canadian Science Writers' Association Science and Health Award for Excellence in Science Journalism. Beth Savan received her doctorate in Ecology from the University of London, England. She is teaching environmental courses at the University of Toronto and is a self-employed enviromental consultant and journalist. an instrument to advance special power and interest. In order to retrieve or develop genuine and open processes of finding and sharing new and old knowledge, it is essential to break through the wall of unquestioning acceptance by citizens of any and all applications of 'science'.... A broadly based and principled critique of science as it is structured and practised today is the essential first step towards a long overdue reformation - the Reformation of Science."

Savan's book is an illustrated argument of how a variety of vested interests affect scientific work. It is suggested that science is in large part a function of the interests it can serve. For scientists "are individuals with personal histories, childhood experiences, phobias, religious and political convictions, hopes, goals, desires and ambitions"... "Scientific investigation is a rather complex series of personal choices and subjective interpretations."

\section{STRUCTURED GROUP APPLICATIONS}

The author defines her object of "exposing the vested interests that drive scientific research, and for reforming scientific administration to encourage more egalitarian, diverse and constructive research."

Is science really a pack of lies? (1). Do we ask the impossible of scientists, to remain skeptical about the theories that they care most passionately about? The late Sir Peter Medawar, Nobel Laureate and experimental pathologist, cautioned in his book 'Advice to A Young Scientist' (2) that researchers should not cling too doggedly to cherished theories, and this led him to advise young scientists "that they should have more than one string in their bow and should be willing to take 'no' for an answer if the evidence points that way". Ms Savan points out that "while the exchange of desperately needed financial support for access to potentially profitable ideas and inventions clearly serves mutual needs, the convergence of academic 
and industrial activities in the scientific-research laboratories is accompanied by a host of ethical, practical, legal and political problems".

\section{CORROSION OF THE COLLEGIAL RELATIONSHIP}

Competition has its many adverse effects, not only because of the conflict between the public's right to know and private interests, but also because of the stringent and often vicious and unhealthy competition for that one of many precious commodities, the research grant. Free discussion of ideas and active collaboration on research projects is essential, but this must be conducted in an atmosphere of trust and harmony. Scientists must be protected from the threat of unemployment by the maintenance of the centuries-old system of tenure. And what becomes of the 'dead wood'? Surely there is no truly 'unproductive' individual, but one who simply needs redirection, refitting and re-encouragement. Older clinicians and scientists are forced to retire while their colleagues in the légal profession become premiers, prime ministers and presidents! This concern for the maintenance of the academic tenure system has been expressed by Auriol Stevens, Public Affairs Director of the British Committee of Vice-Chancellors, who fears that the erosion of the academic-tenure system in England, which guarantees the job security of University professors, will open the way to "bullying of an individual whose research may be thought to threaten important public or commercia interests" (3).

Many of we clinicians who have been involved in targetted or goal oriented medical research have become concerned, and as pointed out by Savan, "the price that we pay for moving research investment from pure to economically motivated research projects won't be known for decades. Eventually, the loss of breadth of new knowledge and the slowed pace of fundamental research findings may constrain fresh advances, and the emphasis on the commercial applications of results may discourage new theoretical synthesis of existing knowledge." If a scientist or clinician manages to secure a long term source of industrial funding, then the question of intellectual independence must be raised. The executive of the Canadian Association of Gastroenterology might consider focusing on this very problem, in which their annual program is heavily subsidized by the pharmaceutical industry, and approximately $50 \%$ of the training of future clinical investigators in gastroenterology in this country will be provided by generous 
support, albeit from a single pharmaceutical company. There is a concern that this process may 'co-opt the experts', a process by which the experts themselves may not recognize that they have lost their objectivity and freedom of action (4).

Why is there such difficulty for the clinician investigator? How often have you heard your young clinician colleague referred to in a negative manner (hopefully not by yourself)? How often have some of us used belittling comments when discussing the contributions and activities of 'the makers of new knowledge' in our department? How often have you heard the young clinician/scientist being referred to as "he (she) isn't a 'real doctor cause he only sees patients part of his time"? When did you last hear a clinical colleague state in a loud and rather obviously negative tone, with regard to a colleague who is truly a promising young investigator and a star on the horizon of the Canadian gastroenterology scene, "... oh well, he's not here today, he's probably off in his lab chopping up rats".

The emotional turmoil experienced by many young investigators is comprised of these many conflicts: the insecurity of their situation, the relative meagreness of their salary support as compared with private practice clinical colleagues, the long years of training, the uncertainties of research funding, the difficulties of 'getting into print', and not the least of which is condescension of colleagues. At least the latter problem is solvable now, today, by a change in attitude. At each point the clinical scientist is under scrutiny, and needs to justify his/her existence. How often have you heard the busy clinician comment in an off-handed fashion "...oh, he's not doing anything these days", when 'he' has just written grant requests, spent the last year painfully and meticulously validating a technique, trained a technician, recruited a graduate student, and published a paper.

This is part of the curency of the investigator, yet 'publish or perish' is itself a problem for science under siege and, as Savan points out, this 'notorious academic cliché embodies the cynicism, even the resentment, of scientists faced with the constant need to show concrete evidence that research time and financial support have not been wasted". But it is not just the number of articles of 'least publishable unit' but rather the quality and impact the investigator's work emphasizes. The stimulation of young minds, the approach to problem solving, the diversion of medical school education from rote memory to problem solving.

Perhaps our clinician colleagues will simply reflect the grow- 
ing public skepticism for science in which, in Savan's view, "science has become politicized: the ideal of rewarding the originality, promise or rigor of a proposal can all too easily be supplemented by familiarity, support for one's own theories or those benefiting powerful interests, and recognition of the applicants and their home institutions... experiments become self fulfilling prophecy. Granting agencies might consider establishing an 'explorations' or 'innovations' grant scheme, for which reviewers would be specifically directed to place a high priority on interdisciplinary investigations that transcend the disciplinary constraints of most granting bodies, original hypotheses, novel research trails, and new or different analyses of existing data. Applicants could also be given an opportunity to reply to reviewers' critiques of their proposals before final granting decisions are made."

When some time ago I made the latter suggestion to a senior colleague, it was smartly excused as being unworkable. Yet during many years of serving on research committees, I have held the unpopular yet uncomfortable view that were an applicant given the chance to reply to the reviewers, all too often simple misunderstandings might be identified and some really good science might be funded. Where do we begin the process of necessary change? "We must begin by acknowledging the sheer number of choices that face research scientists..." and the peer review process, which currently controls most scientific funding and publication decisions, may be at risk of becoming what the philosopher of science, Stephen Toulmin calls a 'gerontocracy' (5), the 'Old Boy Network' of successful scientist with power to determine research priorities, promote favoured theories or hypotheses, and make or break academic careers.

May the controllers of most scientific policy in this country, those who determine the level of research funding, hear the plea that "improved University and research funding is essential in attracting and keeping excellent researchers who would otherwise gravitate to better-equipped and more spacious facilities elsewhere ... to create a better funded but more egalitarian, productive and diverse scientific enterprise... take steps to disengage, as much as possible, the scientists doing research from the vested interest that have a stake in its outcome."
In conclusion, "we must emphasize the importance of human choices in research investigation." Improving science education is one of the best ways to alter the expectations of future scientists and their perceptions of how the research process works. If science education and the publicity surrounding scientific accomplishments take into account the outside pressures on the scientist and the probable effect on the research produced, the ineditability of professional disagreements over scientific evidence could be accepted, if not welcomed. Changes in our expectations of science and scientists will help us to set wise research priorities and use scientific results more effectively. Public disclosure by academic scientists of all corporate, commercial, governmental, and advocacy-group affiliations should be mandatory. University... should all develop conflict-of-interest guidelines that would prohibit individuals from personal financial interests in the field from serving on related peer group committees and from diverting publicly funded findings to private goals. Reform of the peer review process must lie at the heart of any effort to disengage science from the vested interests it can serve. A deliberate effort should be made to balance the backgrounds of reviewers, and journals and granting bodies should seriously consider requiring reviewers to disclose their identities to authors. Applicants and authors should be invited to rate reviewers and they should also be given a chance to reply to carefully explained decisions of their submissions.

And what better time for us, as a professional association and a professional journal, to enter this debate, as now is a time when the very importance of research training and the development of clinician/investigators are being questioned.

\section{REFERENCES}

1. Is Science Really a Pack of Lies? Nature 1983:303:362. (Edit)

2. Medawar PB. Advice To A Young Scientist. New York: Harper and Row, 1979:6.

3. Marks L. Tenure System Under Fire at British Universities. Globe and Mail (Toronto) August 7, 1987, A7.

4. Owen BM, Braeutigam R. The Regulation Game. Cambridge, Massachusetts: Bollinger, 1978:7.

5. Toulmin S. In: Complexity of Scientific Choice, 351. 


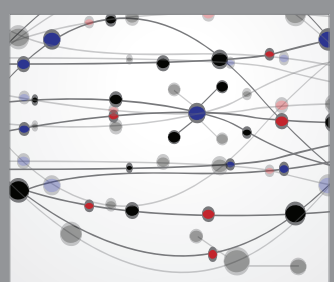

The Scientific World Journal
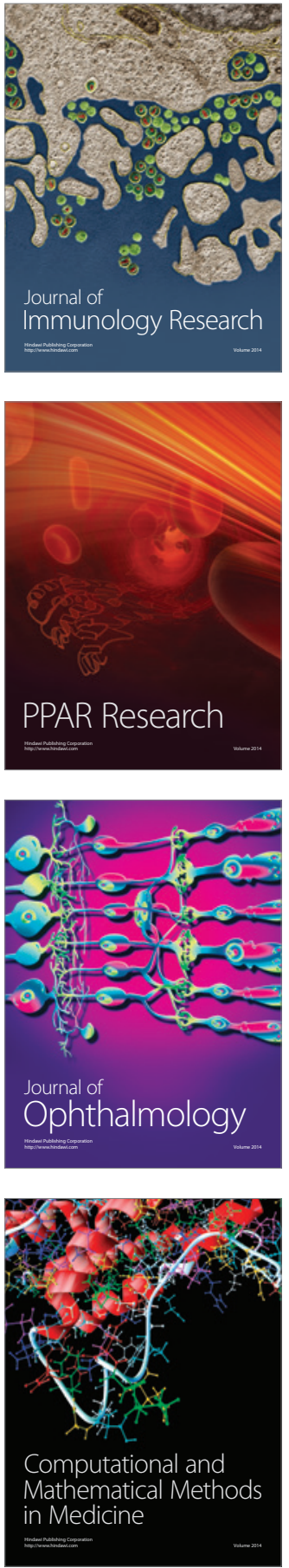

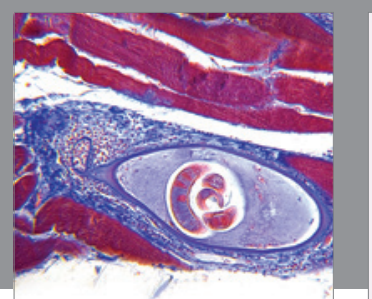

Gastroenterology Research and Practice

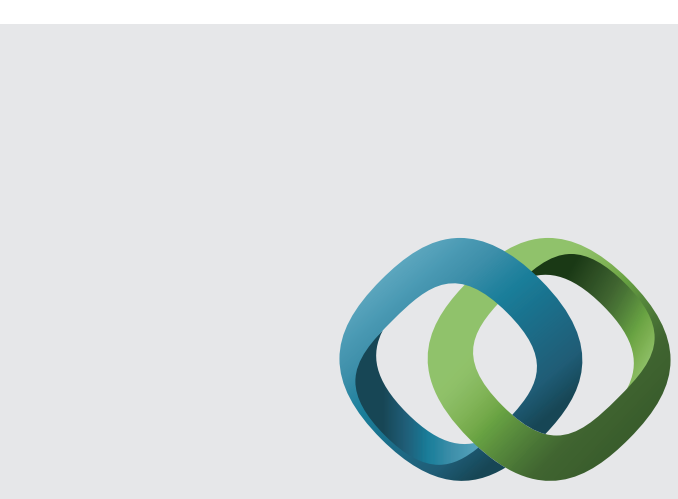

\section{Hindawi}

Submit your manuscripts at

http://www.hindawi.com
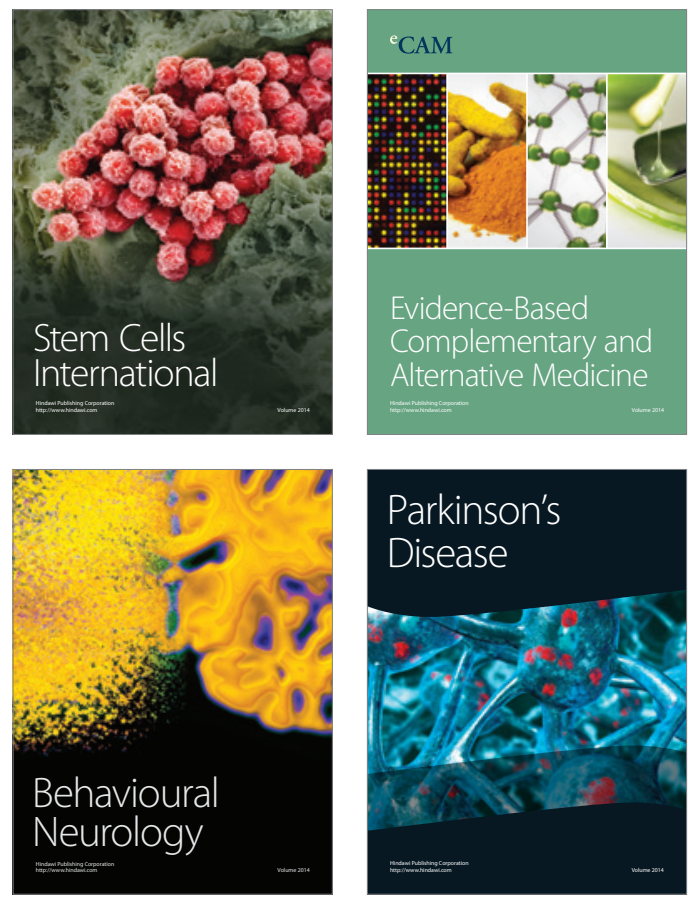
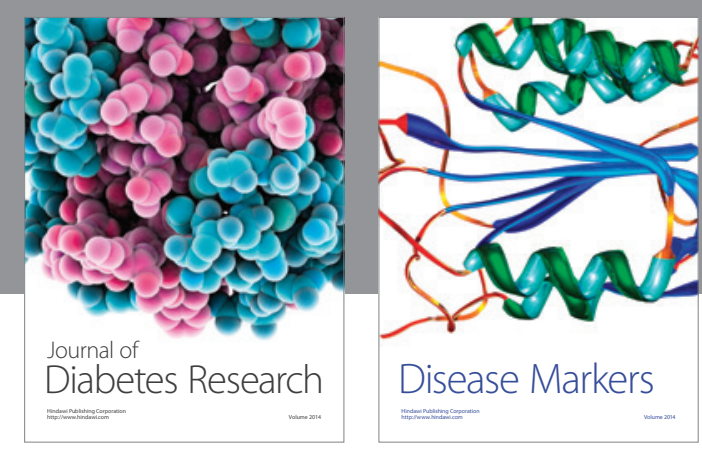

Disease Markers
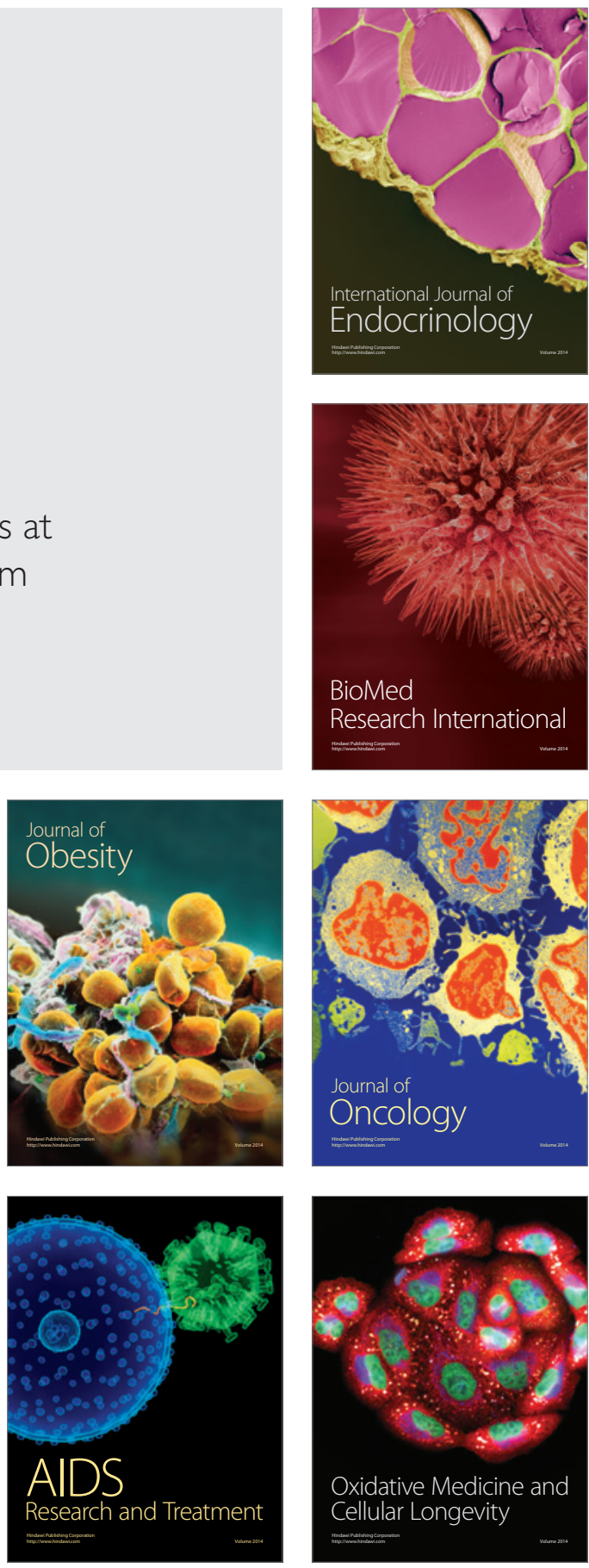